\title{
TÉCNICAS DE ABORDAGEM SOMÁTICA COMO FUNDAMENTO PARA A DANÇA DO CANTOR EM ESPETÁCULOS INTEGRADOS DE CANÇÃO POPULAR
}

\author{
Somatic-approach techniques as a fundamental for the \\ singer's dance in integrated popular song performances
}

\author{
Alexandre Freire da Silva Osorio ${ }^{1}$ \\ Faculdade Santa Marcelina
}

Resumo: Discute-se o papel de técnicas de abordagem somática para o revelar da dança própria do cantor. São apontadas similaridades entre a técnica Klauss Vianna e a técnica vocal desenvolvida por Leila Farah, na busca pela conscientização do caminho do som/movimento no corpo. A vivência conjunta nas duas técnicas estimula um protagonismo por parte do cantor durante o processo criativo de espetáculos de canção, um caminho distinto do percorrido por musicais tradicionais.

Palavras-chave: Processo criativo. Técnicas somáticas. Dança do cantor.

Abstract: The role of somatic approach techniques to reveal the singer's own dance is discussed. Similarities are seen between the Klauss Vianna technique and the vocal technique developed by Leila Farah, in their search for awareness of the path of sound/movement in the body. The joint experience in the two techniques stimulates a leading role during the execution of the creative process of song shows, a distinct path from the one covered by traditional musicals.

Keywords: Creative process. Somatic techniques. Singer's dance.

\footnotetext{
${ }^{1}$ Cantor e dançarino, pós-graduado em Canção Popular pela Faculdade Santa Marcelina (SP).

Moringa Artes do Espetáculo, João Pessoa, UFPB, v. 10 n. 1, jan-jun/2019, p. 89 a 110
}

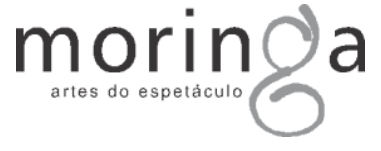


De maneira geral, ainda é pouco disseminada a noção de que a música é uma arte da cena, assim como o teatro e a dança ${ }^{2}$. Ao contrário, é comum o entendimento de que todo o valor da música encerra-se na obra musical em si, desconsiderando-se a influência que a performance do músico possui na produção de sentidos. A escassez de trabalhos sobre a performance dentro da música é percebida até mesmo no campo de estudos da música popular (AUSLANDER, 2004), que abarca manifestações em que a atuação do corpo em cena possui papel central, como por exemplo o rock. Como esclarece Christopher Small:

Essa ideia, de que o significado musical reside exclusivamente em objetos de música, vem com alguns corolários. $O$ primeiro é que a performance musical não desempenha nenhum papel no processo criativo, sendo apenas o meio através do qual o trabalho isolado e autônomo tem de passar

\footnotetext{
2 Apesar deste trabalho tratar de música popular de uma forma geral, sem especificidade de gênero musical, o contexto de interesse é o de música como arte elaborada para ser apresentada ao vivo. Assim, manifestações tais como cantos de trabalho, por exemplo, quando executadas em seu contexto original, não fazem parte do universo deste estudo.
}

para atingir o seu objetivo, o ouvinte. Lemos pouco na literatura de música sobre performance, além do sentido limitado de seguir as anotações do compositor e realizá-las em som, e somos levados a concluir que quanto mais transparente o meio melhor. (SMALL, 2011, p. 5) ${ }^{3}$

No entanto, mesmo em situações com carga performática mais sutil, como o que normalmente acontece, por exemplo, numa apresentação de bossa-nova ou de música de câmara (em contraponto com a eloquência performática de um show de rock, por exemplo), há que se considerar que o músico é um corpo em cena e qualquer movimento, por menor que seja, sempre implica na construção de sentidos. A influência da expressão do corpo do músico em cena sobre o resultado do que é recebido pelo público é tal, que podemos afirmar que o corpo inteiro do músico compõe de forma determinante a expressão da música que ele executa. Quando o músico é cantor, essa relação torna-se ainda mais direta, uma vez que o seu instrumento está contido inteiramente

3 Traduções de citações de obras estrangeiras são do próprio autor deste artigo. 
no seu corpo. Assume-se neste trabalho que o cantor canta com 0 corpo todo, e a expressão dança do cantor é adotada para definir o material primordial da pesquisa.

Estar em cena exige um estado de presença do corpo, que deve estar disponível para as possibilidades do instante atual, constantemente percebendo-se, tanto internamente quanto em relação aos outros corpos com o qual interage e ao espaço onde está inserido. Com efeito, a autopercepção é o fundamento das técnicas de abordagem somática, como a técnica Klauss Vianna, que "é uma técnica de dança com abordagem pedagógica no soma, no sujeito, tornando necessária a interioridade do indivíduo que a pratica, seja ele bailarino, ator, performer, músico, etc." (MILLER, 2012). Na técnica Klauss Vianna, o movimento é algo que se constrói a partir da percepção interior do corpo e da consciência de sua relação com o outro e com o espaço em torno. Busca-se perceber 0 sentido do movimento, como sendo a guia para o seu caminho. A forma do movimento, portanto, não é uma forma exterior, pré-definida. Ao contrário, ela surge a partir de um processo interno de investigação, em que o indivíduo assume a postura de um pesquisador que, apoiado por preceitos técnicos bem definidos, explora as possibilidades do corpo no momento presente, criando assim seus caminhos próprios de movimento.

A técnica vocal também pode ter abordagem somática. De modo análogo ao que ocorre numa técnica somática de dança, uma técnica vocal de abordagem somática tem na percepção interna do caminho do som no corpo a base para que 0 cantor construa o seu som próprio, renunciando à imitação de um padrão exterior tido como ideal. Nessa perspectiva, o refinamento do som acontece na medida da conscientização do seu caminho no corpo do cantor. Aqui também, o trabalho de pesquisa do cantor é constante, uma vez que o corpo presente é conectado ao momento presente, que é perpetuamente mutável, e esse movimento contínuo implica em novas condições, internas 
e externas, para a ressonância do som. Na técnica de canto estudada, desenvolvida por Leila Farah ${ }^{4}$, o som é a guia para o trabalho investigativo. Não é objetivo da pesquisa investigar se se trata de uma técnica que pode ser classificada como somática. Mas podemos afirmar, a partir da prática vivenciada pelo autor tanto na técnica Klauss Vianna quanto na técnica de canto estudada, que há importante similaridade de princípios entre elas, de tal modo que a técnica de canto é considerada como tendo abordagem somática.

Os princípios adotados pelas técnicas de abordagem somática podem funcionar como indutores de uma determinada maneira pela qual processos criativos se estabelecem e se desenvolvem. A vivência concomitante de uma técnica somática corporal e de uma técnica vocal de abordagem somática instiga - cantor a assumir um estado exploratório permanente, de descoberta de caminhos de

\footnotetext{
${ }^{4}$ Após ter feito carreira como cantora lírica, Leila Farah (1935-2014) tornou-se uma das mais requisitadas professoras de canto da cidade de São Paulo (CASOY, 2006), tendo formado vários cantores profissionais. Desenvolveu uma técnica própria, inovadora para a época (MARTINAZZO, 2017).
}

movimento e de som. De criação. Geram-se impulsos para incorporar, junto à cena musical, movimentos que sobrevenham da pesquisa corporal realizada em sala de trabalho. Trata-se, portanto, de um processo criativo que tem na dança do cantor o seu material de base. Nele, a criação é algo que surge internamente, fruto do próprio trabalho investigativo realizado por esse artista-pesquisador, e não a partir de ideias, textos, roteiros ou libretos externamente preconcebidos, colocados de fora para dentro para serem "montados" por um artistaintérprete. Para além da preparação corporal, manifesta-se aqui que a vivência nas técnicas estudadas estimula no artista uma visão de apropriação sobre 0 processo criativo, que então se abre como uma possibilidade de construção de uma obra em que a dança pessoal do cantor seja revelada.

A semente a partir da qual o processo se inicia é variada, podendo ser desde uma simples sequência de movimentos desenvolvida em sala de trabalho a partir, por exemplo, de uma proposta 
de improvisação sobre um dos tópicos corporais definidos pela técnica Klauss Vianna ${ }^{5}$, até uma pesquisa de um repertório de canções sobre uma temática específica. De qualquer forma, a construção se faz usando material do próprio artista, que assim se apropria do processo criativo, sendo a um tempo criador $^{6}$ e intérprete da obra em construção.

O presente trabalho trata especificamente de processos criativos que visam à elaboração de espetáculos de canção popular em

\footnotetext{
${ }^{5}$ A sistematização da técnica Klauss Vianna estruturou sete tópicos corporais: presença, articulações, peso, apoios, resistência, oposições, eixo global. Na fase de introdução da técnica em sala de aula, esses tópicos são abordados de forma a se estabelecer "um jogo de inter-relações com todos eles" (MILLER, 2007, p. 53). "Cada tópico corporal abre a possibilidade de diferentes movimentos, diferentes qualidades corporais, abrindo caminhos interpretativos que vão além do óbvio ao qual normalmente se fica engessado." (BARROS, 2012, p. 74).

6 Podemos assumir como válida a condição de criador mesmo se o processo inclui canções ou textos não-autorais, pois estamos considerando como obra toda a elaboração que está sendo construída como resultado do processo. Nesse sentido, vale ressaltar que no campo da música popular, aos intérpretes é socialmente concedida uma licença que os habilita a criar livremente sobre o que se pode considerar como sendo a obra "original", ou seja, a música na forma como foi elaborada inicialmente (pelo autor da música e pelo autor da letra), ou como foi gravada pela primeira vez.
}

que a música é integrada a outras artes da cena, particularmente a dança e o teatro, mas que não se incluem na categoria de musicais. Existem na literatura trabalhos (e.g. SALZMAN \& DEZI, 2008) que fazem uso do termo genérico novo teatro musical para nomear um tipo de teatro musical que vem sendo desenvolvido desde meados do século $X X$ e que difere em essência das óperas e musicais tradicionais, tanto nos seus aspectos estéticos quanto de concepção. A partir da definição do termo apresentada nesses trabalhos, é possível identificar proximidade conceitual com o tipo de espetáculo de canção popular abordado aqui.

O percurso criativo abordado foi adotado no espetáculo Certos Tipos e suas Canções, do Duo Balangulá (de Campinas, SP), sendo que aspectos do seu processo são analisados. $\mathrm{Na}$ próxima seção são apresentados os princípios das técnicas somáticas, destacando-se aqueles que mais se relacionam com os objetivos da pesquisa, bem como fundamentos da técnica Klauss Vianna e da técnica de canto, e um 
sumário das similaridades de princípios encontradas entre as duas técnicas.

\section{Técnicas de abordagem somática e a dança do cantor}

Esta seção discute de que forma a vivência nas técnicas corporal e de canto estudadas estimulam no cantor, em seus processos criativos, o revelar da sua dança pessoal, pelo trabalho de descoberta da sua voz própria e pela investigação dos seus caminhos próprios de movimento. Essa prática foi adotada no processo criativo do espetáculo Certos Tipos e Suas Canções. Sustenta-se aqui que tal vivência induz a um viés de apropriação do processo pelo cantor, que participa ativamente de todas as suas fases cruciais, como concepção, definição de repertório, criação de arranjos, pesquisa e criação de textos, criação de roteiro, criação coreográfica e criação de cenas.

No universo das técnicas somáticas, o presente trabalho se detém sobre a técnica Klauss
Vianna. A técnica de canto desenvolvida por Leila Farah será apresentada tendo seus fundamentos confrontados com princípios encontrados na técnica Klauss Vianna. Mesmo tendo em vista a similaridade de princípios encontrada, não podemos afirmar que se trata de uma técnica somática, pois isso exigiria um estudo aprofundado, que não é o objetivo do presente trabalho. Antes, o interesse maior aqui é apontar de que forma esse conjunto comum de princípios concorrem para fomentar uma determinada visão sobre processos criativos de espetáculos musicais. A pesquisa se fundamenta em uma vivência tanto na técnica de canto e na técnica Klauss Vianna, quanto no processo criativo de espetáculos de canção popular em que a música é integrada ao teatro e à dança.

\section{Técnicas somáticas}

Técnicas somáticas vêm sendo aplicadas há décadas na preparação de artistas dos mais diversos segmentos das chamadas artes da 
cena, como teatro, dança, performance e música.

Especificamente com relação ao ensino de canto, a técnica Alexander e o método Feldenkrais têm sido empregados, no Brasil e fora dele (BARROS, 2012). Já o emprego da técnica Klauss Vianna no trabalho de canto é bastante recente e como exemplo podemos citar as pesquisas desenvolvidas pela professora Fátima Barros (BARROS, 2012). As técnicas somáticas baseiam-se em quatro principais pontos de articulação (JOLY, 2000, apud BARROS, 2012), a saber:

- A individualidade de cada corpo em movimento: "não há aí um interesse pelo estudo genérico do movimento, mas pela maneira particular que cada corpo se movimenta" (BARROS, 2012, p. 54);

- A inter-relação entre o movimento e o ambiente em que o corpo está integrado: "o ambiente moldando e sendo moldado pelo corpo que se move" (BARROS, 2012, p. 54);
- A relação indissociável entre o sensório e o motor: "é uma prerrogativa da Educação Somática, que se baseia na capacidade de aprendizagem desse sistema sensório-motor" (BARROS, 2012, p. 54);

- A consciência como um acontecimento sensório-motor: "a percepção não poder ser separada do movimento, e o movimento não pode ser separado da percepção - eles são urdidura e trama da personalidade" (HANNA, 1990, apud BARROS, 2012, p. 54).

\section{Sobre a técnica Klauss Vianna}

A técnica Klauss Vianna foi desenvolvida ao longo de quarenta anos no Brasil, tendo sido sistematizada posteriormente por Rainer Vianna e Neide Neves (MILLER, 2007). Nela, a não separação entre técnica e criação é considerada um aspecto fundamental "para o despertar do corpo presente, bem como para a preparação do corpo cênico" (MILLER \& LASZLO, 2016, p. 150). 
A técnica Klauss Vianna propõe uma vivência do soma em estado exploratório, e não uma vivência do corpo mecânico que somente adquire e acumula habilidades. Vivenciamos, mais do que o corpo hábil, o corpo lábil, no sentido de transitório, instável e sempre em transformação, que permite ao artista cênico deixar viva e ativa a postura da investigação necessária ao processo criativo. (MILLER, 2012, p. 73)

O fato de Klauss Vianna ter elaborado sua pesquisa a partir de uma prática em dança foi essencial para a proposta de eliminação da fronteira entre técnica e criação.

Entre as linhas somáticas, a sua técnica apresenta o diferencial de ser a única que chegou à pesquisa anatômica/estrutural, partindo da pesquisa didática/estética de um professor/coreógrafo, permitindo um processo criativo ainda mais permeável, tendo todas as outras técnicas o caminho inverso, pois começaram da pesquisa terapêutica e ampliaram, posteriormente, para a pesquisa estética. (MILLER, 2007, p. 28)

De modo condizente com essa visão, o improviso é rotineiramente usado como forma de vivenciar os princípios da técnica. Criar é atividade cotidiana dentro da técnica Klauss Vianna, que se opõe à perspectiva de reprodução mecânica e automatizada de movimentos, desvinculada da "verdade" e dos desejos do corpo que os executa. Durante uma mesma sessão em sala de trabalho, improvisos são propostos para explorar aspectos de um determinado tópico corporal, inicialmente de forma isolada para, num momento seguinte, serem trabalhados - os aspectos - de forma integrada, provocando no pesquisador a curiosidade de experimentar as relações existentes entre eles. Por exemplo, na abordagem do tópico peso ${ }^{7}$, pode-se inicialmente improvisar tendo como mote a percepção do peso das partes do corpo que participam de um dado movimento e de que forma ela pode contribuir para imprimir leveza a esse movimento, para, num segundo improviso, utilizar a percepção de peso para produzir translações e rotações. Um improviso seguinte pode propor a integração das duas percepções e

${ }^{7} \mathrm{O}$ estudo desse tópico busca a percepção do peso das diversas partes do corpo para compreender qual é o tônus mínimo suficiente para se reagir à força da gravidade. Também investiga-se de que modo pode-se tomar partido do peso para gerar movimento com leveza. 
ser direcionado para a pesquisa conjunta de translações e rotações com leveza de movimentos.

Um trabalho central dentro da técnica é o ganho de espaços corporais. Ganhamos espaços nas articulações na medida que nos libertamos de tensões que limitam os movimentos. A abertura de espaços articulares é bastante exercitada dentro do tópico corporal peso: "Exploramos a independência das articulações por meio da percepção de peso das partes que se relacionam com elas, e não por meio da força e da tensão da musculatura, o que pode resultar na retração da articulação." (MILLER, 2007, p. 57).

A abertura de espaços corporais também libera os movimentos ligados à respiração, pela eliminação das tensões nos músculos intercostais e abdominais que podem dificultar a livre movimentação do diafragma e dos pulmões. Dentro da técnica Klauss Vianna não há recomendações de exercícios específicos para a respiração, uma vez que ela é trabalhada na totalidade do corpo. Segundo o próprio Klauss Vianna:
"Respirar significa abrir, dar espaço. Portanto, subtrair os espaços corporais é o mesmo que impedir a respiração, bloqueando o ritmo livre e natural dos movimentos." (VIANNA, 1990 apud MILLER, 2007, p. 61).

Também com relação às estruturas mais diretamente ligadas ao canto, cabe salientar que o ganho de espaço nas articulações cervicais resulta na liberação da movimentação da laringe, fundamental para uma voz que se pretenda "inteira", isto é, ressonante em toda a sua extensão. Podemos assumir o ganho de espaço corporal como uma condição para revelar a dança do cantor.

Na técnica Klauss Vianna não há nenhum incentivo a atitudes que provoquem comparações de ordem competitiva com o outro. Assume-se que o processo de cada um é único e individual como é o seu corpo, possuindo um tempo e um percurso próprios.

\section{Sobre a técnica de canto}

A técnica de canto abordada no presente trabalho foi desenvolvida 
por Leila Farah e tem sido empregada tanto na música erudita (quer seja canto lírico ou música de câmara) quanto na música popular ${ }^{8}$. Elencam-se aqui alguns dos seus princípios - aqueles que mais interessam dentro das discussões concernentes ao presente trabalho procurando-se apontar as similaridades conceituais que essa técnica possui em relação às técnicas somáticas, mais especificamente a técnica Klauss Vianna. A técnica de canto desenvolvida por Leila Farah foi precursora, no Brasil do início dos anos 1970, da noção de que o cantor "canta com o corpo todo" (MARTINAZZO' ${ }^{9}$ 2017). Antes, a

\footnotetext{
${ }^{8}$ Professores que adotam a técnica - entre eles podemos citar Beatriz Dokkedal e Maurício Martinazzo, além da própria Leila Farah - possuem ou possuíram alunos que atuam no campo da música popular. A própria Leila Farah cantava repertório popular (MARTINAZZO, 2017).

Leila Farah deixou discípulos no ensino da técnica. Entre eles destacamos Maurício Martinazzo, que, além de ter sido seu aluno por dezessete anos, também atuou, por cinco anos, como pianista correpetidor nas aulas de outros alunos. Devido a essa convivência com Leila Farah, aliada à sua longa experiência como professor da técnica, Maurício foi escolhido como a principal fonte de informação sobre a técnica de canto para este trabalho. Concedeu gentilmente uma entrevista ao autor, em que discorreu sobre a sua experiência própria, sobre Leila Farah e sobre os princípios da técnica.
}

atenção ao corpo que o ensino de canto dedicava restringia-se às estruturas corporais associadas ao que se conhece como fonação, como se fossem as únicas responsáveis pela formação e refinamento do som.

Assumir que o cantor canta com o corpo todo implica que um dos princípios da técnica é o respeito à individualidade do cantor, como uma condição fundamental para possibilitar a descoberta da voz própria do cantor, única como único é o seu corpo. Não se tomam modelos externos como sendo padrões de beleza a serem almejados ou mesmo copiados. Ao contrário, o cantor é provocado a constantemente se auto perceber, a aguçar sua sensibilidade para compreender os caminhos de cada som no corpo, a perceber quais são as sensações internas que cada altura de som, cada vogal provoca, o que demanda disponibilidade para assumir um estado exploratório e de conexão com o momento presente, uma vez que o corpo é diferente a cada dia e reage a cada estímulo externo e interno. Como consequência, a individualidade do 
cantor é preservada, como explica Maurício Martinazzo:

A técnica funciona para quem é inexperiente, funciona para quem é experiente, funciona para quem tem uma voz pequena, funciona para quem tem uma voz grande. Porque ela não exige localizações, ela exige espaço (de ressonância do som). E o espaço é dado pelo conhecimento de si mesmo e do seu corpo. (MARTINAZZO, 2017)

O ganho de espaço interno de ressonância da voz é um dos trabalhos essenciais na técnica. Não se deve negar, bloquear, nenhum dos muitos ressoadores do corpo, pois essa é uma condição para que o timbre próprio do cantor se revele e assim se obtenha o que se chama de uma voz "inteira", ou seja, ressonante em toda sua extensão, do grave ao agudo. A abertura de espaço interno para o som é o que vai possibilitar que os harmônicos que caracterizam o corpo que está cantando ressoem, fazendo vibrar todo esse corpo e ampliando suas possibilidades de movimento $^{10}$. A

\footnotetext{
${ }^{10}$ Parte-se aqui do princípio de que canto é movimento. "Cada corpo é um corpo e cada corpo dança sua própria dança. A voz de cada um é moldada por essa dança individual, uma musculatura gerando
}

técnica questiona a noção, comum mesmo nos dias de hoje, de que o trabalho no canto deve almejar uma dada localização para o som, projetando a ressonância de maneira forçada para uma região específica do corpo, geralmente a região frontal do crânio. Conforme Martinazzo (2017), Leila Farah foi vítima de um preconceito atroz no início, porque ninguém sustentava essa tese de que a voz não era (ressoava) na "máscara", não era nos dentes superiores, nos incisivos.

O processo de descoberta da voz própria muitas vezes exige a desconstrução de padrões de emissão previamente fixados, que fazem uso de tensões desnecessárias durante 0 canto. Essa geralmente é uma fase difícil e demorada do aprendizado, pois requer desapego em algum grau de referências estéticas de som que são alheias ao som da voz do aluno. É fundamental que se identifiquem os pontos do corpo onde há emprego de

movimentos que definem estruturas, espaços, pressões, as quais imprimem no ar uma sonoridade que deixa entrever as marcas, a história desses movimentos e a história do movimento é a voz que conta." (BARROS, 2012, p. 39) 
tensões musculares desnecessárias para o canto, pois elas bloqueiam o livre movimento das estruturas que concorrem para a ressonância dos harmônicos.

É comum que se diga que essa é uma técnica em que se canta "no relaxamento". No entanto, é necessário que haja precisão na definição desse conceito, pois relaxamento não pode ser confundido com abandono. Ao contrário, o que se busca é o entendimento de qual é o tônus necessário e suficiente para um canto rico em harmônicos e com texto inteligível. Tanto para que a coluna de ar possa ser sustentada com a intensidade necessária para a ressonância dos harmônicos que compõem a voz que canta e com a qualidade requerida para a projeção que se almeja, quanto para que as formas de cada vogal sejam respeitadas, é necessário que haja ativação muscular com tônus suficiente. Tanto o abandono quanto a tensão são fatores que enrustem o colorido do som e obstruem o caminho para o revelar da voz.

\section{Uma técnica de canto com} abordagem somática

A Tabela 1 apresenta um sumário das similaridades de princípios verificadas entre a técnica Klauss Vianna e a técnica de canto desenvolvida por Leila Farah, a partir das discussões apresentadas nas seções anteriores. Não há com esse empenho nenhuma pretensão em afirmar que se trata de uma técnica somática (o que exigiria um estudo muito mais aprofundado), daí a preferência pelo uso do termo técnica de abordagem somática. Antes, o que existe é o desejo de condensar de forma escrita as conclusões de uma análise, elaborada ao longo de anos de vivência prática, que aponta para uma sinergia entre as duas técnicas que tem guiado os processos criativos do autor, como aconteceu com o espetáculo discutido mais abaixo.

Tabela 1 - Similaridade de princípios entre as duas técnicas 


\begin{tabular}{|c|c|}
\hline técnica Klauss Vianna & técnica de canto \\
\hline individualidade do corpo em movimento & revelar a voz própria do cantor \\
\hline $\begin{array}{l}\text { aluno-pesquisador: autopercepção } \\
\text { contínua das sensações provocadas por } \\
\text { cada movimento }\end{array}$ & $\begin{array}{l}\text { aluno-pesquisador: autopercepção contínua } \\
\text { das sensações provocadas por cada som }\end{array}$ \\
\hline $\begin{array}{l}\text { ganho de espaços corporais para um } \\
\text { movimento desobstruído }\end{array}$ & $\begin{array}{l}\text { ganho de espaços de ressonância para a } \\
\text { projeção do som; não se deve negar nenhum } \\
\text { ressoador do corpo }\end{array}$ \\
\hline $\begin{array}{l}\text { movimento com tônus mínimo suficiente, } \\
\text { sem tensões }\end{array}$ & cantar "no relaxamento", sem tensões \\
\hline $\begin{array}{l}\text { eixo corporal organizado a partir dos } \\
\text { apoios ativos, que utilizam o chão como } \\
\text { base de suporte para o movimento }\end{array}$ & $\begin{array}{l}\text { a coluna de ar, força-motriz que movimenta o } \\
\text { corpo para a produção do som, é assentada } \\
\text { no apoio do diafragma }\end{array}$ \\
\hline $\begin{array}{l}\text { refinamento do movimento ocorre na } \\
\text { medida da conscientização do caminho } \\
\text { que o movimento percorre no corpo }\end{array}$ & $\begin{array}{l}\text { refinamento do som ocorre na medida da } \\
\text { conscientização do caminho que o som } \\
\text { percorre no corpo }\end{array}$ \\
\hline $\begin{array}{l}\text { no lugar de ginásticas virtuosísticas, } \\
\text { respeito aos limites do corpo }\end{array}$ & $\begin{array}{l}\text { os exercícios não devem cansar a voz, mas } \\
\text { ser realizados dentro dos limites do corpo }\end{array}$ \\
\hline
\end{tabular}

Processos criativos de espetáculos integrados de canção popular

O adjetivo integrado é usado aqui no sentido da abertura do processo criativo de espetáculos de canção popular à incorporação de outras artes da cena, mais especificamente dança e teatro. Uma abertura que ocorre não de maneira forçada, ou seja, imposta por condições externas, por uma vontade de se aproximar de um determinado padrão tido como modelo ou por uma ânsia de se estar aderente a algo que se considera contemporâneo, de vanguarda ou da moda. Tal viés não seria somático. A vivência conjunta da técnica Klauss Vianna com a técnica de canto desenvolvida por Leila Farah instiga o cantor a essa abertura, pelo trabalho centrado no respeito à individualidade do corpo 
do cantor e aos seus desejos como criador; pelo incentivo ao movimento criativo; pelo acúmulo que a técnica Klauss Vianna traz em tantos trabalhos já realizados em dança e teatro, história substancial que produz ecos pela sala de trabalho.

Para que haja criação é necessário esvaziamento (MILLER, 2007), preparar o corpo para se abrir ao momento presente para que possa reagir ao que acontece no agora e assim construir o instante seguinte a partir do atual, reiteradamente, gerando um fluxo de movimento $^{11}$. O corpo esvaziado é o corpo neutro, em prontidão para a possibilidade de tudo. As técnicas discutidas no presente trabalho exercitam a escuta para uma regulagem equilibrada do tônus, fundamental para que 0 corpo alcance esse estado de prontidão para o movimento, pois que o tônus prepara o músculo para a contração. Um tônus muito baixo torna lenta a resposta do músculo ao estímulo nervoso, desconectando o corpo do

\footnotetext{
11 Ideia que remete a um dos pontos de articulação das técnicas somáticas: "o ambiente moldando e sendo moldado pelo corpo que se move" (BARROS, 2012, p. 54).
}

momento presente, enquanto que um tônus muito alto provoca fadiga e desperdício de energia.

\section{Um certo tipo de teatro musical}

Os gêneros artísticos mais lembrados quando se pensa em espetáculos em que a música é integrada à dança e ao teatro são a ópera e o musical. No entanto, as possibilidades dessa integração são inúmeras, indo bastante além dos padrões estabelecidos por essas duas modalidades. Eric Salzman e Thomas Desi usam o termo novo teatro musical para designar um tipo de teatro musical desenvolvido a partir de meados do século $X X$, inicialmente na Europa e nos Estados Unidos. De modo geral, os autores definem o termo da seguinte forma:

Teatro musical é um teatro que é orientado pela música (ou seja, vinculado decisivamente ao tempo e à organização musical) onde, no mínimo, a música, a linguagem, a vocalização e o movimento físico existem, interagem ou se situam lado a lado em algum tipo de igualdade, mas realizados por diferentes artistas e em um ambiente social diferente daquele dos trabalhos normalmente classificados como óperas 
(interpretados por cantores de ópera em casas de ópera) ou musicais (interpretados por cantores de teatro em teatros “legítimos"). (SALZMAN \& DESI, 2008, p. 5)

Uma grande parte dos trabalhos enquadrados nesse conceito rejeitam a grandiosidade encontrada em óperas e musicais. Os motivos são variados, indo desde razões econômicas até preferências estéticas (a preferência por vozes não projetadas e por instrumentação diferente daquela utilizada em óperas e musicais; a escolha por teatros pequenos, com maior proximidade com o público; etc.) ou mesmo político-ideológicas. Vozes não projetadas e instrumentação não convencional (em relação à tradição em óperas e musicais), como ocorre na música popular, implicam geralmente no uso de amplificação, mesmo em teatros pequenos. $\mathrm{O}$ trabalho de Eric Salzman e Thomas Desi debruça-se com mais atenção sobre a música erudita, mas os princípios analisados se aplicam também a espetáculos de música popular, como é o caso do presente trabalho.
No tipo de espetáculo tratado aqui, busca-se uma relação de maior proximidade com o público, privilegiando-se a apresentação em espaços menores e com instrumentação reduzida. De modo que, no limite, o espetáculo pode ser realizado até mesmo em formato de solo. Também não há um roteiro que seja guiado por um libreto preconcebido, como acontece nas óperas e musicais. Ao contrário, o texto $^{12}$ é criado pelos próprios artistas que estarão em cena e a narrativa vai sendo construída ao longo do processo criativo a partir de estímulos levados por eles para dentro da sala de trabalho, e/ou a partir de improvisos. Os arranjos musicais também são desenvolvidos no decorrer do processo criativo, pelos próprios artistas que estarão em cena. É comum que à medida que o processo avança e que ideias sejam incluídas ou modificadas, os arranjos musicais e até mesmo o

\footnotetext{
12 O sentido dado aqui à palavra texto é similar ao dado por Eric Salzman e Thomas Desi. "A palavra também pode ser entendida como o conceito ou conceitos a partir dos quais a obra é derivada, a intenção ou intenções que moldam os 'sobre' e os 'como' da obra futura." (SALZMAN \& DESI, 2008, p. 333, tradução nossa)
} 
repertório passe por revisões. O arranjo musical é um elemento importante dentro do processo criativo e sua concepção induz a conformações na composição da cena.

\section{Certos Tipos e Suas Canções}

A ideia inicial do espetáculo Certos Tipos e Suas Canções surgiu de uma pesquisa de repertório feita pelo Duo Balangulá, que levantou canções brasileiras de várias épocas da história da canção gravada, com uma temática comum, ou seja, cada canção narra, em terceira pessoa, uma situação cotidiana vivida por um personagem específico. Os tipos descritos nessas pequenas crônicas incluem, por exemplo, um valente que fazia as mulheres suspirarem, lamentando sua orientação homossexual (Mulato Bamba, de Noel Rosa - 1932), um policial vaidoso que gostava que o chamassem de "o maior inspetor de quarteirão" (Cabo Tenório, de Rosil Cavalcante - 1957), ou um vaqueiro aposentado que reflete sobre a sua decadência na velhice (Bom
Vaqueiro, de João do Vale - 1976).

O caráter de "contação" de histórias que essa temática sugere foi exercitado corporalmente em sala de trabalho com o suporte provocativo de textos selecionados pelo duo, que foram sendo integrados ao processo, ora inteiros, ora de forma fragmentada, configurando cenas curtas que aos poucos foram surgindo.

A criação das cenas teve orientação na técnica Klauss Vianna, no âmbito de um curso livre de teatro. Com o suporte de uma preparadora corporal e um diretor cênico, as cenas do espetáculo começaram a ser criadas a partir de material surgido internamente ao processo. A metodologia incluiu um treinamento energético dentro do processo de preparação corporal, no início de toda sessão de trabalho, com o intuito de despertar o corpo para o momento presente, no sentido de conduzir o corpo em direção ao corpo neutro. $O$ processo se estendeu após a finalização do curso, tendo continuado com o mesmo diretor cênico do curso. A atuação do diretor cênico do 
espetáculo foi fundamental para que as cenas criadas durante o processo pudessem ser sequenciadas conjuntamente às canções, de forma coerente.

O roteiro, criado coletivamente (duo e diretor) durante o processo, foi sendo elaborado à medida que o processo avançava, com a criação das cenas e a elaboração dos arranjos (criados pelo duo) acontecendo de forma concomitante, o que acabou resultando no estabelecimento de "climas" ao longo do espetáculo. Esses climas delimitaram seções, cada uma constituída por um conjunto de canções e cenas associadas, com uma concepção de iluminação própria. As seções são alternadas no decorrer do espetáculo, ora de forma a estabelecer contrastes, ora com relações mais consonantes. É interessante perceber que nas apresentações, muitas vezes o público aplaude somente ao final de cada seção, e não ao final de cada música, como é mais comum em espetáculos de canção popular. A Figura 1 traz um instante da seção inicial do espetáculo, de clima intimista, formada por quatro canções de cunho rural-interiorano, amalgamadas por um texto que faz uma reflexão sobre o processo de envelhecimento de um vaqueiro. Com som amplificado, o espetáculo possui sonoridade acústica, com instrumentação formada por vozes, violão, violas brasileiras, contrabaixo acústico e percussão.

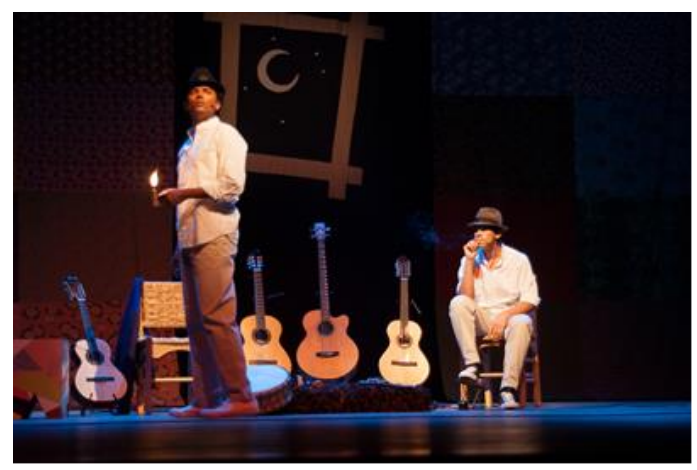

Figura 1 Cena da seção inicial do espetáculo. Foto: Denise Maher

A permeabilidade assumida durante o processo criativo de Certos Tipos e Suas Canções abriu espaço no processo criativo para a integração na cena de ações diversas como cantar, tocar instrumentos, dançar e falar. A vivência nas técnicas de abordagem somática estudadas foi um fator importante para se lidar com 
essa diversidade. Por exemplo, para os momentos em que o canto é simultâneo a outros movimentos (como tocar, andar, sentar, levantar, abaixar, etc.), foi importante a ativação da percepção do assim denominado oitavo vetor ${ }^{13}$, que possibilita um ganho de espaço na região cervical, evitando o surgimento de tensões em torno da laringe, que de outra forma seriam bastante prováveis de acontecer devido à simultaneidade de ações com o canto, o que multiplica os focos de atenção do cantor. Além disso, verificou-se que a clareza de texto e a abertura de espaços de ressonância do som, trabalhados na técnica de canto, puderam ser diretamente aplicados também nos momentos em que textos eram falados, e não somente durante o canto.

É interessante perceber que não há cansaço vocal ou corporal ao final de cada apresentação, apesar de se tratar de um espetáculo fisicamente

${ }^{13} \mathrm{Na}$ técnica Klauss Vianna, trabalha-se a percepção de direções ósseas como forma de organizar o eixo global do corpo. São definidos oito vetores de direções ósseas. O oitavo vetor localiza-se na sétima vértebra cervical e é associado ao alinhamento entre o crânio e a caixa torácica. (MILLER, 2007) exigente, pela diversidade de ações realizadas pelos dois cantores e também pela extensão vocal de uma boa parte das canções. O ganho de espaço de ressonância para o som durante o trabalho de preparação permite uma emissão sem tensão e com menor pressão de ar, assim como o ganho de espaço articular possibilita o uso equilibrado do tônus muscular, evitando esforços desnecessários.

\section{Conclusões}

Técnicas de abordagem somática propõem uma escuta atenciosa do corpo, percebendo, para cada movimento realizado e para cada som cantado, quais são as sensações provocadas. Um caminho na direção da busca da voz própria ou, de forma mais geral, da dança própria do cantor, o que pressupõe acolhimento à individualidade e aos desejos desse corpo. O presente trabalho apresentou uma visão sobre a influência que a preparação corporal fundamentada em técnicas de abordagem somática pode possuir em processos criativos de 
espetáculos de canção popular, tornando-os permeáveis a impulsos provocados por uma perspectiva sobre a consciência do movimento que implica na apropriação da criação pelo cantor. Criação que nasce a partir de movimentos internos que, fundando raízes, abrem espaço para que essas projeções internas se exteriorizem. Como observa Klauss Vianna: "À medida que vou sentindo o solo, empurrando o chão, abro espaço para minhas projeções internas, individuais, que, à medida que se expandem, me obrigam a uma projeção para o exterior." (VIANNA, 1990, p. 78, apud MILLER, 2007).

Conceber a voz sendo movimento é uma decorrência do despertar do cantor para o fato de que a totalidade do seu corpo interfere no canto. Ao adotar a escuta do corpo como prática, o cantor assume um estado de pesquisa em que investiga de que forma as diversas partes do seu corpo interagem na produção de cada movimento e como um movimento pode influir no próximo. Busca entender como o seu corpo pode melhor se organizar para produzir o movimento/som desejado. Dessa forma, ele compreende que o ganho de espaços articulares é análogo ao ganho de espaços de ressonância; desperta para a possibilidade de produção de movimento e de som sem que haja emprego de tensões desnecessárias; percebe que 0 movimento surge a partir dos apoios do corpo no chão, assim como é pelo apoio do diafragma que se sustenta a coluna de ar que produz o som. Durante esse trabalho de pesquisa, associações são feitas, pontes são construídas. O cantor reconhece que a organização do eixo global do corpo influi na produção do som, que a percepção dos apoios do corpo produz efeitos no ganho de espaços internos de ressonância do som, etc. A similaridade de princípios verificada de forma prática entre as duas técnicas estudadas permite afirmar que a sua vivência conjunta pode cooperar de forma determinante na busca da dança própria do cantor.

A canção popular é um fértil terreno de criação. Ao longo de sua história, ela tem sido transformada, alargada 
e reinventada de diversas maneiras.

No presente trabalho, buscou-se discutir de que forma um processo criativo que tem no soma um fundamento pode propiciar com que haja um transbordamento do espetáculo de canção popular em sua forma tradicional em direção a um espetáculo em que a música se integra à dança e ao teatro. Um hibridismo que se instaura de maneira orgânica, em decorrência dos fluxos internos surgidos durante o processo, e não por uma tentativa de cópia de modelos externos. Esses fluxos aos poucos se expandem, dando origem a movimentos, roteiros, arranjos musicais, cenas, sons.

Recebido em 16/01/2019

Aceito em 28/02/2019

\section{Referências Bibliográficas}

AUSLANDER, Philip. Performance analysis and popular music: a manifesto. Contemporary Theatre Review, Vol. 14(1), 2004

BARROS, Maria de Fátima Estelita. Canto como expressão de uma individualidade. Tese de Doutorado. Instituto de Artes. Campinas: Unicamp, 2012.
CASOY, Sergio. Ópera em São Paulo, 1952-2005. São Paulo: EdUSP, 2006.

HANNA, Thomas. Clinical Somatic Education - A new discipline in the field of healthcare. Somatics, Novato, CA, v.8(1), Autumn-Winter, 1990.

JOLY, Yvan. The Feldenkrais Method of Somatic Education. Feldenkrais Journal UK, Jan. 2000.

MARTINAZZO, Maurício. Jundiaí: 2017. Entrevista concedida ao autor.

MILLER, Jussara. Qual é o corpo que dança? Dança e educação somática para adultos e crianças. São Paulo. Summus. 2012

MILLER, Jussara. A Escuta do corpo: sistematização da técnica Klauss Vianna. São Paulo. Summus. 2007

MILLER, Jussara; LASZLO, Cora. A sala e a cena: a importância pedagógica de processos criativos em dança e educação somática. Cadernos do GIPE-CIT PROCESSOS CRIATIVOS: Educação Somática e Afetos, Salvador, № 36, 2016.

MOLINA, Sergio Augusto. A composição de música popular cantada: a construção de sonoridades e a montagem dos álbuns no pós-década de 1960. Tese de Doutorado. Universidade de São Paulo. 2014

SALZMAN, Eric; DESI, Thomas. The new music theater: seeing the voice, hearing the body. Oxford University Press, 2008. 
SMALL, Christopher. Musicking:

The meanings of performing and

listening. Wesleyan University

Press, 2011.

VIANNA, Klauss. A Dança. São

Paulo. Summus Editorial, 1990.

ZUMTHOR, Paul. Peformance, recepção e leitura. São Paulo.

Cosac Naify. 2016 
Moringa Artes do Espetáculo, João Pessoa, UFPB, v. 10 n. 1, jan-jun/2019, p. 89 a 110

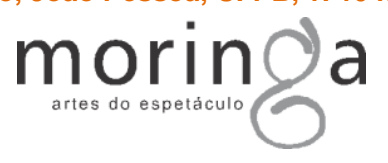

